\title{
Cardiac device-related infective endocarditis in the Czech Republic: Prospective data from the ESC EORP EURO-ENDO registry
}

\author{
Jan Latala ${ }^{\mathrm{a}}$, Michal Pazdernikb,c, Maria Holicka ${ }^{\mathrm{d}}$, Radek Pelouche, Jiri Widimskyf, Jiri Pudich ${ }^{\mathrm{g}}$, Radek Vancata ${ }^{\mathrm{h}}$, Michal Siraneci, \\ Kamila Blechova ${ }^{\mathrm{j}, \mathrm{k}}$, Tadeas Buttac', Marketa Mikulcova ${ }^{\mathrm{m}}$, Michal Mikulica ${ }^{\mathrm{m}}$, Peter Wohlfahrt" ${ }^{\mathrm{n}}$, Martin Hutyra ${ }^{\mathrm{a}}$, Jan Precek ${ }^{\mathrm{a}}$
}

Aim. Understanding cardiac electronic device infective endocarditis epidemiology is essential for the management of this serious complication. Only monocentric and limited data have been published regarding patients in the Czech republic so far. The aim of this study was to describe the current profile, microbiology and clinical characteristics of this population.

Patients and Methods. National data from the prospective ESC-EORP EURO-ENDO registry were collected. 57 consecutive patients with a diagnosis of cardiac device-related infective endocarditis (CDRIE) from 11 Czech centres were included.

Results. Staphylococcus spp. was responsible for $43.9 \%$ of isolates, whereas Culture negative endocarditis was documented in $26.3 \%$ episodes. The most frequent complications under therapy were acute renal failure (17.5\%), septic shock and heart failure (both 10.5\%). Extraction of device was performed in $75.4 \%$ of all patients, and the 1 -year mortality was $22.5 \%$.

Conclusions. The high proportion of culture-negative endocarditis is alarming and warrants further investigation. Cardiac device related infective endocarditis is a serious complication with a high 1-year mortality in a highly polymorbid spectrum of patients.

Key words: cardiac electronic device infective endocarditis, infective endocarditis, cardiac device complication

Received: November 19, 2020; Revised: January 29, 2021; Accepted: February 1, 2021; Available online: February 22, 2021 https://doi.org/10.5507/bp.2021.013

(c) 2022 The Authors; https://creativecommons.org/licenses/by/4.0/

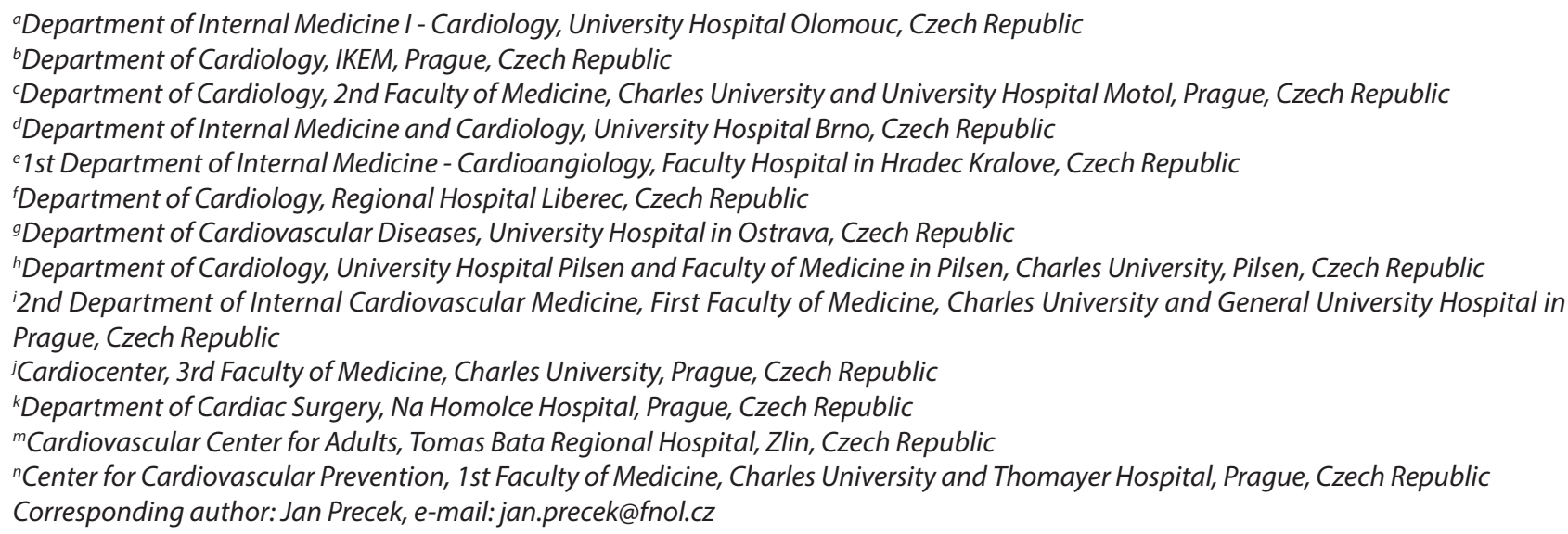

\section{INTRODUCTION}

Contemporary, cardiac device-related infective endocarditis (CDRIE) is a serious public health problem. With the growing number of implanted devices, we also face a disproportionately growing incidence of CDRIE (ref. ${ }^{1}$ ). The treatment of infectious complications is both financially and time demanding; in the US, the treatment costs per patient and year exceed sixty-thousand dollars ${ }^{2}$. We can predict a surge in the incidence and prevalence of CDRIE owing to an ageing population, higher proportion of immunocompromised and polymorbid patients, as well as the increasing complexity of procedures. The morbidity and mortality is doubled in CDRIE compared to patients without infective complications and surprisingly, the increased mortality persists even after successful treatment of CDRIE ( ref. $^{3}$ ), and is comparable to mortality owing to infective endocarditis ${ }^{4}$. To date, there are no consistent multicentric data on the infective complications of this device therapy in the Czech Republic. In this study, we present a subanalysis of ESC-EORP EURO-ENDO registry of cardiac device related infective endocarditis in the Czech Republic, which includes consecutive patients from the majority of tertiary care cardiovascular centres in the country in a selected timeframe. 


\section{METHODS}

\section{Study design and data collection}

All data were collected from the prospective multicentre ESC-EORP EURO-ENDO registry. The detailed methodology of EURO-ENDO has already been report$\mathrm{ed}^{4}$. All consecutive patients aged $\geq 18$ years with definite or possible IE were included, from April 2016 to March 2018. All participants signed informed consent. Patients from 11 main tertiary care cardiac centres in the Czech Republic were collected - Prague (Institute for Clinical and Experimental Medicine-IKEM, Faculty Hospital Kralovske Vinohrady, Faculty Hospital Motol, General Faculty Hospital), Faculty Hospital Brno Bohunice, Faculty Hospital Olomouc, Faculty Hospital Ostrava, Faculty Hospital Plzeň, Faculty Hospital Hradec Králové, Regional Hospital Liberec and Regional Hospital Zlín.

\section{Baseline and follow-up data}

Baseline data included clinical characteristics, biological and microbiological data, imaging data, treatment before admission and during hospitalization, complications under therapy, theoretical indication for surgery (as reported by responsible practitioners), in-hospital surgery/ procedures performed (including both percutaneous and surgical procedures to remove infected intracardiac material), in-hospital mortality. 1-year follow-up data were obtained based on either a telephone call or a clinical examination.

\section{Statistical analysis}

Continuous data with normal distribution are presented as mean \pm SD (standard deviation), non-normally distributed variables as median (interquartile range - IQR). Categorical data are shown as frequencies and percentages. Between-group differences were tested using analysis of variance (ANOVA), Kruskal-Wallis, chi-square tests or Fisher exact test, as appropriate.

Calculations were done using SPSS version 21 (IBM SPSS Statistics, IBM Corporation, Armonk, New York). All statistical tests were 2-sided with a significance level of 0.05 .

\section{RESULTS}

In total, 57 consecutive patients with discharge diagnosis of CDRIE have been enrolled. Baseline characteristics of patients and risk factors are summarized in Table 1 . Median age of patients was 67 years, $22.8 \%$ of them were women. $50.8 \%$ of patients suffered from diabetes. Majority of patients (64.9\%) were implantable cardioverter defibrillator (ICD) or cardiac resynchronization therapy defibrillator (CRT-D) recipients. Median time from symptoms onset to diagnosis reached 21 days (6-44).

Clinical presentation of patients and suspected source of infection are summarized in Table 2. Fever was present in 43 patients $(75.4 \%)$, heart failure was the second most prevalent syndrome on admission. The most frequent complications on admission were embolic events, which
Table 1. Patient demographics and characteristics.

\begin{tabular}{|c|c|}
\hline \multicolumn{2}{|l|}{ Demographics } \\
\hline Age (years) median & $67(60,71)$ \\
\hline Females $(\%)$ & $13(22.8)$ \\
\hline \multicolumn{2}{|l|}{ Type of implanted device } \\
\hline Pacemaker (\%) & $20(35.1)$ \\
\hline $\operatorname{ICD}(\%)$ & $26(45.6)$ \\
\hline CRT-D (\%) & $11(19.3)$ \\
\hline \multicolumn{2}{|l|}{ History of $\mathrm{CV}$ disease } \\
\hline Heart failure & $31(54.4)$ \\
\hline Congenital heart disease & $2(3.5)$ \\
\hline Ischemic heart disease & $32(56.1)$ \\
\hline Atrial fibrillation & $25(43.9)$ \\
\hline HOCM & $1(1.8)$ \\
\hline Dilated cardiopathy & $11(19.3)$ \\
\hline Known heart murmur & $13(22.8)$ \\
\hline Previous IE (\%) & $2(3.5)$ \\
\hline \multicolumn{2}{|c|}{ Non-cardiac interventions (last 6 months) } \\
\hline Dental procedure & $1(1.8)$ \\
\hline GIT procedure & $1(1.8)$ \\
\hline \multicolumn{2}{|l|}{ Risk factors } \\
\hline Diabetes melitus & $29(50.9)$ \\
\hline Previous stroke/TIA & $9(15.8)$ \\
\hline Hypertension & $39(68.4)$ \\
\hline COPD/asthma & $9(15.8)$ \\
\hline Chronic renal failure & $15(26.3)$ \\
\hline Haemodialysis & $6(10.5)$ \\
\hline Chronic autoimmune disease & $3(5.3)$ \\
\hline Cancer & $2(3.5)$ \\
\hline Smoking & $12(21.1)$ \\
\hline IVDA & $0(0)$ \\
\hline Alcohol abuse & $2(3.5)$ \\
\hline Immunosuppressive treatment & $1(1.8)$ \\
\hline Long corticotherapy & $3(5.3)$ \\
\hline \multicolumn{2}{|l|}{ Anticoagulant treatment } \\
\hline VKA (\%) & $11(19.3)$ \\
\hline DOAC $(\%)$ & $4(7.0)$ \\
\hline APA (\%) & $31(54.4)$ \\
\hline LMWH (\%) & $9(15.8)$ \\
\hline VKA/DOAC/LMWH + APA (\%) & $4(7.0)$ \\
\hline
\end{tabular}

COPD, chronic obstructive pulmonary disease; HOCM, hypertrophic obstructive cardiomyopathy; ICD, implantable cardioverter defibrillator; IE, infective endocarditis; IVDA, intravenous drug abuse; PM, pacemaker; TIA, transient ischemic attack; VKA, vitamin K antagonist; DOAC, direct oral anticoagulation; APA, antiplatelet agents; LMWH, low molecular weight heparin

occurred in 8 patients (14\%) and conduction abnormalities $(n=6,10.5 \%)$.

Basic microbiology results are displayed in Fig. 1. The most prevalent microorganisms were Staphylococcus aureus in 15 patients (26.3\%) and Coagulase negative staphylococci in 10 patients (17.5\%). No positive blood cultures were detected in 15 patients $(26.3 \%)$.

Complications during therapy are summarized in Table 3. The most frequent complications were acute renal failure in 10 patients (17.5\%), septic shock and heart failure (both in $10.5 \%$ ). 
Extraction of cardiac devices was performed during hospitalization in $43(75.4 \%)$ patients, among them 30 $(52.6 \%)$ were percutaneous, $12(21.1 \%)$ surgical and a combination of both was indicated in 1 patient $(1.8 \%)$. In 14 patients, neither percutaneous nor surgical extraction has been performed - in 4 patients due to refusal, in 7 because of exceedingly high surgical risk and in 3 because of death before procedure was reported.

In-hospital mortality was relatively low in patients with CDRIE, as only 4 patients deceased (7.1\%), one patient was lost to follow-up. In contrast, one-year mortality reached $22.5 \%$ (9 patients) with 17 patients lost to follow-up.

\section{DISCUSSION}

This is, to our knowledge, the first multicentre registry of CDRIE in the Czech Republic. To date, only institutional, uni-center experience with CDRIE has been reported $^{5,6}$.

The incidence of CDRIE can be expected in a relatively wide range of 0.5-15 cases per 1000 patient years, and effects predominantly polymorbid patients ${ }^{7,8}$. We agree with that as more than half of our patients presented with history of diabetes, ischaemic heart disease and heart failure. Men are more frequently affected than women ${ }^{9}$, in our cohort they represented $77.2 \%$ of all patients. Several risk factors for infection development have been described - such as the type of device, while ICDs having more than twice the risk of pacemakers ${ }^{8}$, replacement or repeated procedures and patient related characteristics - age, diabetes, chronic obstructive pulmonary disease, steroid use, history of previous device infection, heart failure, renal insufficiency, or anticoagulant medication use ${ }^{10}$. In our study, most of patients had ICD or CRT-D implanted, showing an apparent discrepancy with population distribution of implanted devices, in which pacemakers are 4 times more prevalent than ICDs' (ref. ${ }^{11}$ ). Of note, no patient in our study was active intravenous drug abuser, which is an established risk factor for right sided endocarditis $^{12}$. No significant link was found in relation to recent invasive procedures including dental ones, which further reinforces recommendation to consider patients with implantable devices as in low or intermediate risk for hematogenous spread of infection and thus no need for antibiotic prophylaxis before surgical procedures ${ }^{13}$.

In principle, pathogen can reach an implanted device within days as a direct inoculation at the time of implantation or as a hematogenous spread of infection. The first way is much more common, which explains higher percentage of staphylococcus strain in device endocarditis specimens ${ }^{14,15}$. This was also our case with staphylococcus strain comprising almost half of positive findings - almost identically as in previous Czech retrospective series, which has not been limited only to CDRIE (ref. ${ }^{16}$ ). In $26 \%$ of cases no causative microorganism was found, which correspond to other published data ${ }^{17}$. There are several explanations for culture negative infective endocarditis, ranging from non-adequate blood and tissue cultures sam-
Table 2. Clinical presentation.

\begin{tabular}{lc}
\hline & CDRIE $(\mathrm{n}=57)$ \\
\hline Signs and symptoms & \\
Fever & $43(75.4)$ \\
Cough & $17(29.8)$ \\
Dizziness & $13(22.8)$ \\
Cerebrovascular event & $1(1.8)$ \\
Syncope & $1(1.8)$ \\
Cardiac murmur & $18(31.6)$ \\
Congestive heart failure & $21(36.8)$ \\
Septic shock & $1(1.8)$ \\
Days from onset of symptoms to diagnosis & $21(6-42)$ \\
\hline Complications on admission & \\
Abscess & $4(7.0)$ \\
Spondylitis & $1(1.8)$ \\
Conduction abnormality & $6(10.5)$ \\
Embolic events & $8(14)$ \\
$\quad$ Pulmonary & $5(8.8)$ \\
Cerebral & $1(1.8)$ \\
Splenic & $1(1.8)$ \\
Peripheral & $1(1.8)$ \\
Suspected source of Infection & \\
Health care associated IE & $10(17.5)$ \\
Nosocomial & $5(8.8)$ \\
Non-nosocomial & $12(21.1)$ \\
Community acquired & $29(50.9)$ \\
\hline
\end{tabular}

ICD, implantable cardioverter defibrillator; IE, infective endocarditis; PM, pacemaker

Table 3. Complications under therapy.

\begin{tabular}{lc}
\hline & CDRIE (n=57) \\
\hline Embolic events & $3(5.3)$ \\
$\quad$ Pulmonary & $2(3.5)$ \\
Spleen & $1(1.8)$ \\
Spondylitis & $1(1.8)$ \\
CHF & $6(10.5)$ \\
Cardiogenic shock & $4(7.0)$ \\
Septic shock & $6(10.5)$ \\
Acute renal failure & $10(17.5)$ \\
Persistent fever & $3(5.3)$ \\
Positive blood cultures after $48 \mathrm{~h}$ & $4(7.0)$ \\
Increasing vegetation size & $4(7.0)$ \\
Thrombopenia $(<10000)$ & $1(1.8)$ \\
\hline
\end{tabular}

CHF, congestive heart failure; ICD, implantable cardioverter defibrillator; PM, pacemaker

pling, microorganism difficult to cultivate and empirical antibiotic therapy in time of blood sampling. Moreover in our study we have not performed lead tip tissue cultivation nor pocket tissue cultivation, techniques proven to be the most sensitive ${ }^{18}$.

Serious complications unrelated to extraction procedure are rather uncommon in CDRIE. In contrast to leftsided endocarditis, in which we frequently see marked structural and systemic complications ${ }^{4,19}$. Even pulmonary embolism is fairly rare in CDRIE setting with only $3.5 \%$ 


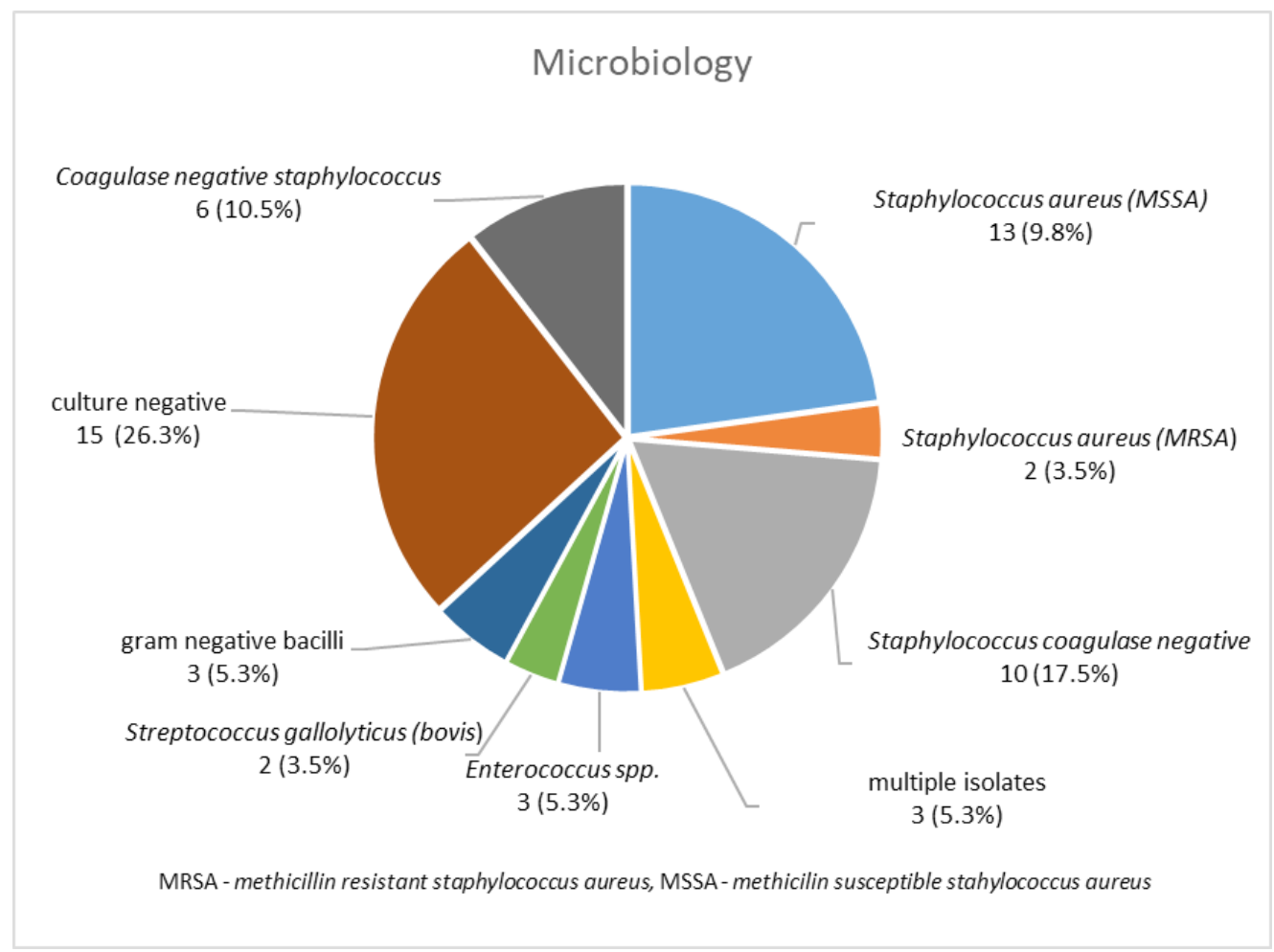

Fig. 1. Microbiology results.

percent of patients affected, which is in concordance with other series $^{20}$. In our study $10.5 \%$ of patients suffered from septic shock, which also corresponds to results of EURO-ENDO study ${ }^{4}$.

Complete extraction of whole device is essential for prognosis improvement and long-term infection control $^{21}$, especially when staphylococcus spp. is the causative microorganism. In our study no extraction has been performed in 14 patients $(24.5 \%)$. Proportion is slightly higher than in comparable series ${ }^{17}$, but lower than in EURO-ENDO whole population, in which up to $34.6 \%$ of patients did not undergo any procedure ${ }^{4}$. An analysis whether on site availability of either percutaneous extraction techniques or surgery has any impact on decision regarding extractions could be helpful, however in our case most ( 9 out of 11) centres have either cardiac surgery or extraction capability.

A relatively low in-hospital mortality was found in our cohort $(7.1 \%)$, however 1-year mortality reached $22.5 \%$, which is concordance with previously published Czech experience by Binova et al. (ref. ${ }^{6}$ ), demonstrating serious impact of CDRIE on a long-term survival of already highly polymorbid cohort of patients. Complete extraction of infected device is essential to tackle the high mortality of CDRIE, which was shown in previous studies ${ }^{20,22,23}$, in contrast, patients treated conservatively exhibit the highest mortality ${ }^{24}$.

\section{CONCLUSIONS}

Device infections remain one of the most dreadful complications of modern-era device therapy. High pro- portion of culture-negative endocarditis is alarming and warrants further investigation. CDRIE represents a serious complication with high 1-year mortality in already highly polymorbid spectrum of patients.

\section{LIMITATIONS}

We cannot guarantee that all centres really included all their patients consecutively and prospectively, since the study was based on the volunteer participation of each centre.

As most centres being tertiary referral centres with cardiac surgical programmes, thus the profile of the cases might have been affected by referral bias.

Marked proportion of patients, who lost to follow, which might have affected long term mortality outcomes.

Acknowledgement: Supported by MH CZ - DRO (RIV 87-85, FNOL, 00098892).

Author contributions: JL, MP: manuscript writing, literature search, data analysis and interpretation, data collection - investigators of EURO-ENDO registry, final manuscript approval; MHo, RP, JW, JPu, RV, MS, KB, TB, MaMi, MiMi, PW: data collection - investigators of EURO-ENDO registry, final manuscript approval; $\mathrm{MHu}$ : criticial revision, final manuscript approval; JPr: data collection - investigator of EURO-ENDO registry, criticial revision, final manuscript approval

Conflict of interest statement: None declared. 


\section{REFERENCES}

1. Voigt A, Shalaby A, Saba S. Continued rise in rates of cardiovascular implantable electronic device infections in the United States: Temporal trends and causative insights. PACE - Pacing Clin Electrophysiol 2010;33:414-9.

2. Greenspon AJ, Eby EL, Petrilla AA, Sohail MR. Treatment patterns, costs, and mortality among Medicare beneficiaries with CIED infection. Pacing Clin Electrophysiol 2018;41:495-503.

3. Rizwan Sohail M, Henrikson CA, Jo Braid-Forbes M, Forbes KF Lerner DJ. Increased long-term mortality in patients with cardiovascular implantable electronic device infections. PACE - Pacing Clin Electrophysiol 2015;38:231-9.

4. Habib G, Lancellotti P, Erba PA, Sadeghpour A, Meshaal M, Sambola A, Furnaz S, Citro R, Ternacle J, Donal E, Cosyns B, Popescu B, lung B, Prendergast $B$, Laroche $C$, Tornos $P$, Pazdernik M, Maggioni A, Gale $C P_{1}$ Ali Tatar-Chentir NN, Al-Mallah M, Astrom Aneq M, Athanassopoulos G, Badano LP, Benyoussef S, Calderon Aranda E, Cardim NM, Chan KL, Cosyns B, Cruz I, Edvardsen T, Goliasch G, Habib G, Hagendorff A, Hristova K, lung B, Kamp O, Kang DH, Kong W, Matskeplishvili S, Meshaal M, Mirocevic M, Neskovic AN, Pazdernik M, PlonskaGosciniak E, Popescu BA, Prendergast B, Raissouni M, Ronderos R, Sade LE, Sadeghpour A, Sambola A, Sengupta S, SeparovicHanzevacki J, Takeuchi M, Tucay E, Tude Rodrigues AC, Varga A, Vaskelyte J, Yamagata K, Yiangou K, Zaky H, Granada I, Mahia M, Ressi S, Nacinovich F, Iribarren A, Fernandez Oses P, Avegliano G, Filipini E, Obregon R, Bangher M, Dho J, Cartasegna L, Plastino ML, Novas V, Shigel C, Reyes G, De Santos M, Gastaldello N, Granillo Fernandez M, Potito M, Streitenberger G, Velazco P, Casabé JH, Cortes C, Guevara E, Salmo F, Seijo M, Weidinger F, Heger M, Brooks R, Stöllberger C, Ho CY, Perschy L, Puskas L, Binder C, Rosenhek R, et al. The ESC-EORP EURO-ENDO (European Infective Endocarditis) registry. Eur Hear J - Qual Care Clin Outcomes 2019;5:202-7.

5. Vlašínová J. Cardiac device-related infection - A new epidemic? Cor Vasa 2010;52:62-6.

6. Bínova J, Kubánek M, Sedláček K, Krýže L, Kautzner J. Cardiac implanted electronic device-related infective endocarditis. Interv a Akutni Kardiol 2017;16:146-50.

7. Jędrzejczyk-Patej E, Mazurek M, Kowalski O, Sokal A, Kozieł M, Adamczyk K, Przybylska-Siedlecka K, Morawski S, Liberska A, Szulik M, Podolecki T, Kowalczyk J, Kalarus Z, Lenarczyk R. Device-related infective endocarditis in cardiac resynchronization therapy recipients - Single center registry with over 2500 person-years follow up. Int J Cardiol 2017;227:18-24.

8. Özcan C, Raunsø J, Lamberts M, Køber L, Lindhardt TB, Bruun NE, Laursen ML, Torp-Pedersen C, Gislason GH, Hansen ML. Infective endocarditis and risk of death after cardiac implantable electronic device implantation: a nationwide cohort study. EP Eur 2017;19:1007-14.

9. Aydin M, Yildiz A, Kaya Z, Kaya Z, Basarir AO, Cakmak N, Donmez I, Morrad B, Avci A, Demir K, Cagliyan EC, Yuksel M, Elbey MA, Kayan F, Ozaydogdu N, Islamoglu Y, Cayli M, Alan S, Ulgen MS, Ozhan H. Clinical Characteristics and Outcome of Cardiovascular Implantable Electronic Device Infections in Turkey. Clin Appl Thromb 2014;22:459-64.

10. Polyzos KA, Konstantelias AA, Falagas ME. Risk factors for cardiac implantable electronic device infection: A systematic review and meta-analysis. Europace 2015;17:767-77.

11. Raatikainen MJP, Arnar DO, Merkely B, Nielsen JC, Hindricks G, Heidbuchel H, Camm J. A Decade of Information on the Use of Cardiac Implantable Electronic Devices and Interventional Electrophysiological Procedures in the European Society of
Cardiology Countries: 2017 Report from the European Heart Rhythm Association. EP Eur 2017;19:ii1-90.

12. Moss $R$, Munt $B$. Injection drug use and right sided endocarditis. Heart 2003;89:577-81.

13. Habib G, Lancellotti $P$, Antunes MJ, Bongiorni MG, Casalta JP, Del Zotti F, Dulgheru R, El Khoury G, Erba PA, lung B, Mirob JM, Mulder BJ, Plonska-Gosciniak E, Price S, Roos-Hesselink J, Snygg-Martin U, Thuny F, Mas PT, Vilacosta I, Zamorano JL, Erol C, Nihoyannopoulos P, Aboyans V, Agewall S, Athanassopoulos G, Aytekin S, Benzer W, Bueno H, Broekhuizen L, Carerj S, Cosyns B, De Backer J, De Bonis M, Dimopoulos K, Donal E, Drexel H, Flachskampf FA, Hall R, Halvorsen S, Hoenb B, Kirchhof $P$, Lainscak M, Leite-Moreira AF, Lip GYH, Mestresc CA, Piepoli MF, Punjabi PP, Rapezzi C, Rosenhek R, Siebens K, Tamargo J, Walker DM. 2015 ESC Guidelines for the management of infective endocarditis. Eur Heart J 2015;36:3075-123.

14. Bluhm G, Nordlander R, Ransjö U. Antibiotic Prophylaxis in Pacemaker Surgery: A Prospective Double Blind Trial with Systemic Administration of Antibiotic Versus Placebo at Implantation of Cardiac Pacemakers. Pacing Clin Electrophysiol 1986;9:720-6.

15. Da Costa A, Lelièvre $H$, Kirkorian $G$, Célard $M$, Chevalier $P$, Vandenesch $\mathrm{F}$, Etienne J, Touboul P. Role of the preaxillary flora in pacemaker infections: a prospective study. Circulation 1998;97:1791-5.

16. Pazdernik M, Baddour LM, Pelouch R. Infective endocarditis in the Czech Republic: Eight years of experience at one of the country's largest medical centers. J Heart Valve Dis 2009;18:395-400.

17. Kim DH, Tate J, Dresen WF, Papa FC, Bloch KC, Kalams SA, Ellis CR Baker MT, Lenihan DJ, Mendes LA. Cardiac implanted electronic device-related infective endocarditis: Clinical features, management, and outcomes of 80 consecutive patients. PACE - Pacing Clin Electrophysiol 2014;37:978-85.

18. Tarakji KG, Chan EJ, Cantillon DJ, Doonan AL, Hu T, Schmitt S, Fraser TG, Kim A, Gordon SM, Wilkoff BL. Cardiac implantable electronic device infections: Presentation, management, and patient outcomes. Hear Rhythm 2010;7:1043-7.

19. Pazdernik M, Wohlfahrt P, Kautzner J, Kettner J, Sochman J, Stasek J, Solar M, Pelouch R, Vojacek J. Clinical predictors of complications in patients with left-sided infective endocarditis: A retrospective study of 206 episodes. Bratislava Med J 2019;120:510-5.

20. Osmonov D, Ozcan KS, Erdinler I, Altay S, Yildirim E, Turkkan C, Ekmekci A, Gungor B, Gurkan K. Cardiac device-related endocarditis: 31-Years' experience. J Cardiol 2013;61:175-80.

21. Blomström-Lundqvist C, Traykov V, Erba PA, Burri H, Nielsen JC, Bongiorni MG, Poole J, Boriani G, Costa R, Deharo JC, Epstein LM, Sághy L, Snygg-Martin U, Starck C, Tascini C, Strathmore N. European Heart Rhythm Association (EHRA) international consensus document on how to prevent, diagnose, and treat cardiac implantable electronic device infections-endorsed by the Heart Rhythm Society (HRS), the Asia Pacific Heart Rhythm Society (APHRS), th. Eur Heart J 2020;41:2012-32.

22. Gutiérrez Carretero $E$, Arana Rueda E, Lomas Cabezas JM, Laviana Martínez F, Villa Gil-Ortega M, Acosta Martínez J, Pedrote Martínez A de Alarcón González A. Infections in Cardiac Implantable Electronic Devices: Diagnosis and Management in a Referral Center. Rev Española Cardiol (English Ed 2017;70:355-62.

23. Polewczyk A, Jacheć W, Polewczyk AM, Tomasik A, Janion M, Kutarski A. Infectious complications in patients with cardiac implantable electronic devices - risk factors, prevention and prognosis. Polish Arch Intern Med 2017; 127(9):597-607. doi: 10.20452/pamw.4065

24. Del Río A, Anguera I, Miró JM, Mont L, Fowler VG, Azqueta M, Mestres CA. Surgical Treatment of Pacemaker and Defibrillator Lead Endocarditis: The Impact of Electrode Lead Extraction on Outcome. Chest 2003;124:1451-9. 